Article

\title{
Novel Motion Sickness Minimization Control via Fuzzy-PID Controller for Autonomous Vehicle
}

\author{
Sarah `Atifah Saruchi ${ }^{1}{ }^{(D}$, Mohd Hatta Mohammed Ariff ${ }^{1, *}$, Hairi Zamzuri ${ }^{1,2}$, \\ Noor Hafizah Amer ${ }^{3}$, Nurbaiti Wahid ${ }^{4}$, Nurhaffizah Hassan ${ }^{4}$ and Khairil Anwar Abu Kassim ${ }^{5}$ \\ 1 MalaysiaJapan International Institute of Technology, Universiti Teknologi Malaysia, \\ Kuala Lumpur 54100, Malaysia; satifah2@liveutm.onmicrosoft.com (S.'A.S.); \\ hairi.kl@utm.my or hairi@moovita.com (H.Z.) \\ 2 eMoovit Technology Sdn Bhd, Futurise Centre, Cyberjaya 63000, Malaysia \\ 3 Faculty of Engineering, Universiti Pertahanan Nasional Malaysia, Kuala Lumpur 57000, Malaysia; \\ noorhafizah@upnm.edu.my \\ 4 Faculty of Electrical Engineering, Universiti Teknologi MARA, Dungun 23000, Malaysia; \\ nurbaiti@uitm.edu.my (N.W.); nurhaffizah@uitm.edu.my (N.H.) \\ 5 Malaysian Institute of Road Safety Research (MIROS), Kajang 43000, Malaysia; khairilanwar@miros.gov.my \\ * Correspondence: mohdhatta.kl@utm.my
}

Received: 25 May 2020; Accepted: 6 July 2020; Published: 10 July 2020

check for updates

\begin{abstract}
In terms of vehicle dynamics, motion sickness (MS) occurs because of the large lateral acceleration produced by inappropriate wheel turning. In terms of passenger behavior, subjects experience MS because they normally tilt their heads towards the direction of lateral acceleration. Relating these viewpoints, the increment of MS originates from the large lateral acceleration produced by the inappropriate wheel's turn, which then causes greater head movement with respect to the lateral acceleration direction. Therefore, this study proposes the utilization of fuzzy-proportional integral derivative (PID) controller for an MS minimization control structure, where the interaction of the lateral acceleration and head tilt concept is adopted to diminish the lateral acceleration. Here, the head movement is used as the controlled variable to compute the corrective wheel angle. The estimation of the head movement is carried out by an estimation model developed by the radial basis function neural network (RBFNN) method. An experiment involving a driving simulator was conducted, to verify the proposed control system's performance in regard to the autonomous vehicle's passengers. The results show that the averages of motion sickness incidence (MSI) index can be lowered by $3.95 \%$ for single lap and $11.49 \%$ for ten laps.
\end{abstract}

Keywords: autonomous vehicle; fuzzy-PID; head roll angle; lateral acceleration; motion sickness minimization; radial basis function neural network

\section{Introduction}

The autonomous vehicle is one of the rapidly evolving technologies that offer enhancement in mobility and positive contributions in terms of environmental impact [1,2]. However, the transfer of control from the driver to an autonomous system can trigger motion sickness (MS), an uncomfortable sensation that will negatively affect the user acceptance [3]. It has been reported that MS is one of the human factor issues that needs a finer understanding, so that vehicle automation can be successfully introduced [4]. Thus, this study focuses on the MS issue in an autonomous vehicle.

It is well-known that drivers experience less MS than the passengers. In terms of the behavior of the occupants, the factors of MS include the sensory conflict theory and postural instability [5]. However, this current study was inspired by the findings of Wada et al. whose method was straight 
forward and thus easy to understand. Those authors stated that the dissimilar head tilt movements by both driver and passenger towards the direction of the lateral acceleration influenced their MS susceptibility [6,7]. The same authors also proved that in slalom driving conditions, the head roll angle and lateral acceleration are correlated to each other. As depicted in Figure 1, in cornering situations, the passengers are more likely to tilt their heads according to the direction of lateral acceleration while the drivers are more likely to tilt their heads against the direction. An understanding of the interaction of head tilt direction and lateral acceleration is important toward the study of MS minimization. The passengers can mitigate their MS level by imitating the driver's head tilt direction or by reducing their head tilt or head roll angle towards the lateral acceleration direction. For example, a postural device has been successfully invented to reduce the passenger's head roll angle during curve driving [8,9]. However, instead of using devices, implementing a vehicle control system appears to be more practical and less pricey.

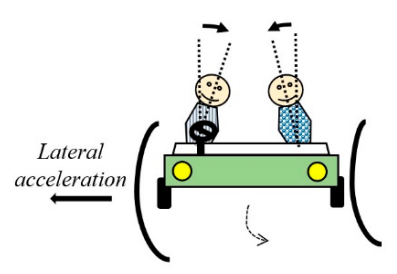

Figure 1. General head movement of the occupants.

In terms of vehicle dynamics, the primary factor of MS is the lateral acceleration generated by the driver's turning skill. The greater the lateral acceleration produced by the driver, the greater the possibility that the passengers experience MS [10]. Thus, Elbanhawi et al. proposed that a smooth vehicle lateral control system can solve the MS issue [11]. Improvement in the lateral control system for an autonomous vehicle can be achieved by integrating a path tracking controller with a path planner [12], dynamic speed adaptation (DSA) [13] and torque vectoring control [14]. Besides combining the path tracking controller with a high-computation control system, the lateral system can also be improved by simply adding a corrective wheel angle to the vehicle. The wheel corrector scheme is known as active steering system, where an additional angle is generated based on the controlled variables which are normally selected from the vehicle states like yaw rate and side slip [15].

Saruchi et al. succeeded in proposing the development of a MS minimization control strategy, by introducing an estimated head roll angle to represent the controlled variable to produce a corrective wheel angle [16]. The proposed control strategy is based on the MS occurrence factors from occupant behavior and vehicle dynamic perspectives. The goal of the control strategy is to diminish the lateral acceleration to minimize the passenger's head roll angle, which will subsequently mitigate their level of MS. However, the study only applied a conventional fuzzy logic controller (FLC) as the corrective wheel angle generator. The other drawback of the study is that it only tested the MS mitigation control system in simulation. Therefore, to extend the previous study, the main contribution of this study is to propose the utilization of a fuzzy-proportional integral derivative (PID) controller to compute the corrective wheel angle and also to evaluate the proposed system in the hardware platform by using driving simulator.

PID is a well-known conventional controller that is simple and reliable [17]. However, the shortcoming of the conventional PID is its difficulty in controlling nonlinear and higher-order plants [18]. FLC mimics human perception in decision making, which turns it into an effective method to be applied in the nonlinear system [19]. One of FLC advantages is that it does not require the mathematical definition of the control plant beforehand. It has been reported that the hybrid combination of a FLC and a PID, which known as fuzzy-PID has better control performance than the conventional controller alone [20].

In the MS minimization control strategy, the estimated driver's head roll angle is treated as the desired response while the estimated passenger's head roll angle is used as the actual response. The reasons of using estimated responses are due to the absence of the driver in the autonomous vehicle 
and the impracticality of attaching motion sensors on the passengers during travel. The implementation of the estimated head roll to represent the controlled variable can be realized by developing a prediction model to produce the estimated head roll responses. As mentioned before, it is a fact that the occupant's head roll angle has correlation with the lateral acceleration. Hence, head roll estimation can be carried out by establishing a model that represents the correlation. The correlation model will be used to predict the head roll responses based on the information of lateral acceleration. In previous research works, the correlation model had been established by system identification (SI) [21,22], artificial neural network (ANN) [23], time delay neural network (TDNN) [24] and radial basis function neural network (RBFNN) methods [25]. The success of the application of the head roll prediction model developed by the RBFNN method in MS minimization control system is proven by Saruchi et al. [16]. Thus, similarly, this study implemented the RBFNN method to produce the prediction model. The prediction model is taken from the previous work, with the details of the modeling process available in Reference [25].

\section{Methodology}

\subsection{Structure of the Proposed MS Minimisation Control Strategy}

Figure 2 depicts the proposed MS minimization control structure. It consists of an outer and an inner loop system. The outer loop is a path tracking system, where the vehicle tracks the desired coordinates, $x_{r e f}, y_{\text {ref }}$ and heading, $\varphi_{\text {ref }}$. The system applies a Stanley controller to obtain the wheel angle, $\delta_{s}$ from the information of lateral error, $e$ and heading error, $\varnothing$. $e$ is computed based on the desired coordinates, $x_{r e f}, y_{r e f}$ and the current vehicle coordinates, $x_{c}, y_{c}$ while $\varnothing$ is calculated based on the desired heading, $\varphi_{\text {ref }}$ and the current heading, $\varphi$.

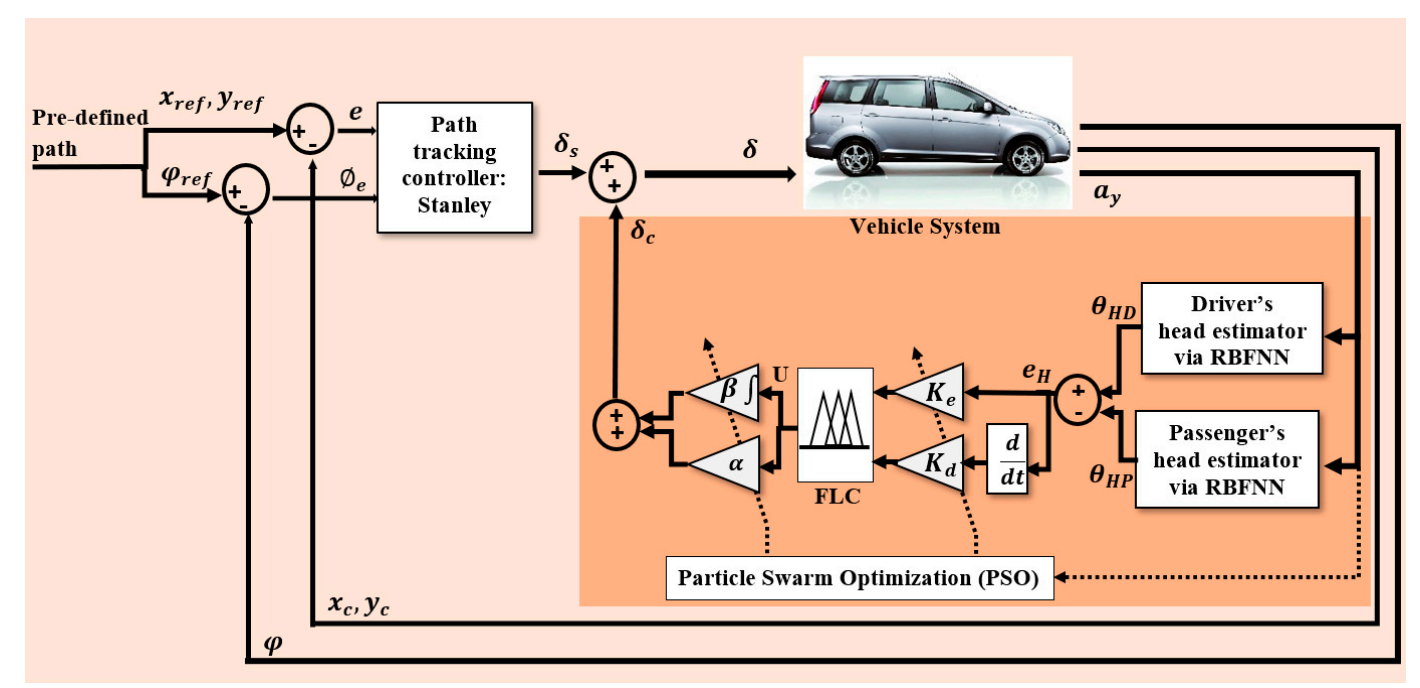

Figure 2. The proposed control structure.

Based on Figure 2, the focus of this study is the usage of fuzzy-PID controller in the inner loop with a dedicated purpose to compute an additional corrective wheel angle, $\delta_{\mathcal{c}}$ to diminish the lateral acceleration, $a_{y}$. The scaling factors, $K_{e}, K_{d}, \beta, \alpha$ of the Fuzzy-PID are optimized by using particle swarm optimization (PSO) to acquire the optimal values. The corrective wheel angle, $\delta_{c}$ is computed by the fuzzy-PID controller. The inputs for the fuzzy-PID are head roll error, $e_{H}$ and derivative head roll error, $\dot{e}_{H}$. The responses of estimated driver's and passenger's head roll angles, $\theta_{H D}, \theta_{H P}$ represent desired and actual responses. The difference between these responses is calculated to compute head roll error, $e_{H}$.

Both head roll responses are estimated by RBFNN modeling method. The input of the RBFNN prediction model is the lateral acceleration, $a_{y}$. An experiment is carried out to provide data for the 
modeling process. Lastly, the wheel angle generated by the path tracking, $\delta_{s}$ and the corrective wheel angle produced by Fuzzy-PID controller, $\delta_{c}$ are totaled and become the final wheel angle input, $\delta$.

\subsection{Outer Loop: Nonlinear Vehicle Model}

Figure 3 shows the illustration of the 7-degrees-of-freedom (DOF) nonlinear vehicle system model that is utilized in this study. The vehicle model consists of 3-DOF to represent the vehicle in the lateral, longitudinal and yaw motion with 1-DOF contributing to the rotational motion of each wheel.

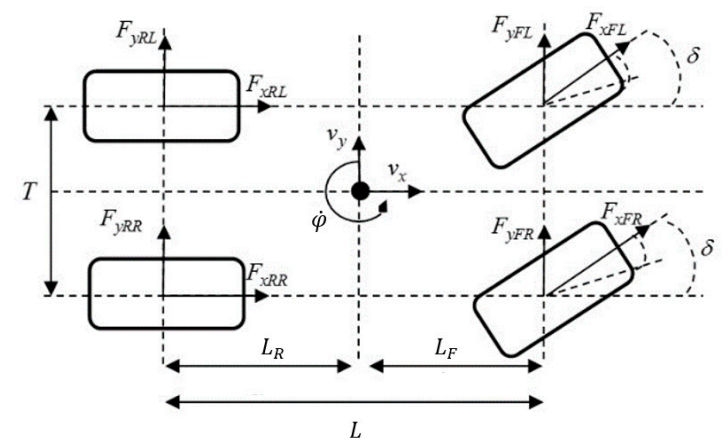

Figure 3. Vehicle model.

Based on Figure 3, the governing equations of the model are expressed as follows [26]:

$$
\begin{gathered}
m\left(v_{y}+v_{x} \dot{\varphi}\right)=\left(F_{y F L}+F_{y F R}\right) \cos \delta+\left(F_{x F L}+F_{x F R}\right) \sin \delta+F_{y R L}+F_{y R R} \\
m\left(\dot{v}_{x}-v_{y} \dot{\varphi}\right)=\left(F_{x F L}+F_{x F R}\right) \cos \delta-\left(F_{y F L}+F_{y F R}\right) \sin \delta+F_{x R L}+F_{x R R} \\
I_{z} \ddot{\varphi}=L_{F}\left(\left(F_{y F L}+F_{y F R}\right) \cos \delta+\left(F_{x F L}+F_{x F R}\right) \sin \delta\right)-L_{R}\left(F_{y R L}+F_{y R R}\right)+\frac{T}{2}\left(\left(-F_{x F L}+F_{x F R}\right) \cos \delta+\left(F_{y F L}-F_{y F R}\right) \sin \delta-F_{x R L}+F_{x R R}\right)
\end{gathered}
$$

where $v_{y}$ and $v_{x}$ are the lateral and longitudinal velocities and $\dot{\varphi}$ is the yaw rate. $F_{x i}$ and $F_{y i}$ $(i=F R, F L, R R, R L)$ are the wheel's longitudinal and lateral forces.

The vehicle model consisted of quasi-static load transfer to generate normal force generations. The normal load equations are given by:

$$
\begin{aligned}
& F_{z F L, F R}=m g \frac{L_{R}}{2 L}-\frac{m a_{x} h}{2 L} \mp \frac{m a_{y} h}{2 T} \\
& F_{z R L, R R}=m g \frac{l_{f}}{2 L}+\frac{m a_{x} h}{2 L} \mp \frac{m a_{y} h}{2 T}
\end{aligned}
$$

where $g$ is the gravitational acceleration, $h$ is the centre of gravity height, $a_{x}$ is the longitudinal acceleration, $a_{y}$ is the lateral acceleration and $T$ is the track width.

The vehicle system used nonlinear wheel model whereas the equations can be referred in [27]. Table 1 tabulates the vehicle model parameters.

Table 1. Parameter of vehicle model.

\begin{tabular}{cccc}
\hline Symbol & Definition & Value & Unit \\
\hline$v_{y}, v_{x}$ & Lateral and longitudinal velocities & 30 & $\mathrm{~km} / \mathrm{h}$ \\
$T$ & Track width & 1.53 & $\mathrm{~m}$ \\
$L_{F}, L_{R}$ & Front and rear wheel distance to COG & $1.26 \& 1.9$ & $\mathrm{~m}$ \\
$m$ & Vehicle mass & 2023 & $\mathrm{~kg}$ \\
$I_{z}$ & Yaw inertia & 6286 & $\mathrm{~kg} \cdot \mathrm{m}^{2}$ \\
\hline
\end{tabular}




\subsection{Outer Loop: Stanley Controller}

Figure 4 shows the configuration of the Stanley controller which applied in the path tracking control system. The Stanley controller produces the wheel angle, $\delta_{s}$ based on the desired trajectory.

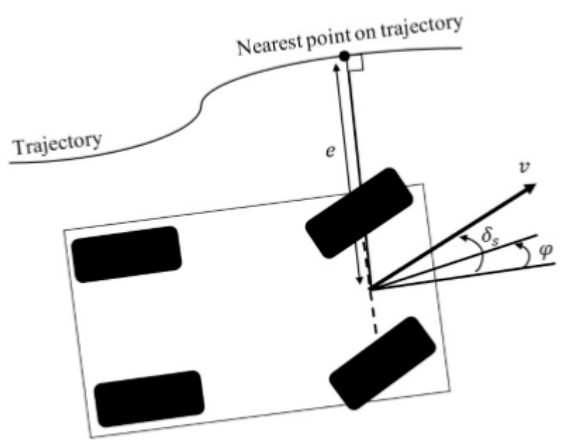

Figure 4. Stanley's configuration.

Based on Figure 4, the control law of the Stanley can be derived as follows [28]:

$$
\delta_{s}(t)=\varnothing+\tan ^{-1}\left(\frac{k_{s} e(t)}{v(t)}\right)
$$

where $k_{s}$ is the gain parameter.

The control law in (6) is saturated by $\delta_{\max }$ as demonstrated in (7). Considering the limitation of the system in delivering fast response, $\delta_{\max }$ is set to be $\pm 17^{\circ}$ in both directions. This is the region in which the wheel is tested and managed to achieve satisfactory performance in the matter of accuracy and delay.

$$
\delta_{s}(t)=\left\{\begin{array}{cl}
\delta_{\text {max }} & \text { if } \varnothing+\tan ^{-1}\left(\frac{k_{s} e(t)}{v(t)}\right) \geq \delta_{\max } \\
\varnothing+\tan ^{-1}\left(\frac{k_{s} e(t)}{v(t)}\right) & \text { if }\left|\varnothing+\tan ^{-1}\left(\frac{k_{s} e(t)}{v(t)}\right)\right|<\delta_{\text {max }} \\
-\delta_{\text {max }} & \text { if } \varnothing+\tan ^{-1}\left(\frac{k_{s} e(t)}{v(t)}\right) \leq \delta_{\max }
\end{array}\right.
$$

At this juncture, the value of $k_{s}$ was determined by simulating the outer loop of the proposed control structure using the pre-defined path in Figure 5. The slalom path is derived from the average driving pattern during the data collection experiment. The details of the experiment will be elaborated later in Section 2.4. Based on the saturation limit in (7), the appropriate value of $k_{S}$ chosen here is 4.3.

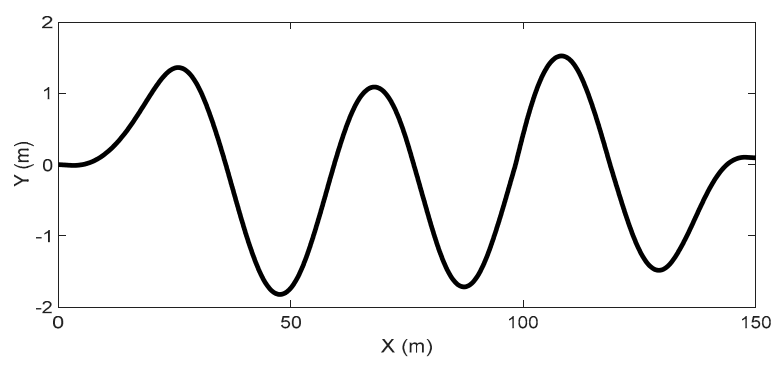

Figure 5. Pre-defined path.

\subsection{Radial Basis Function Neural Network (RBFNN) Modeling}

Figure 6 depicts the structure of the RBFNN. It has a single input layer, a single hidden layer consists of Gaussian radial basis function and a single output layer. The network input, $x$ is used as the input for all functions in the hidden layer, each with different parameters. Meanwhile, the network output, $y$ is a linear combination of the outputs of Gaussian functions. In this study, the driver's and 
the passenger's models are trained and modeled separately. Therefore, $x$ is the lateral acceleration, $a_{y}$ and $y$ is either the response driver's head roll, $\theta_{H D}$ or passenger's head roll, $\theta_{H P}$.

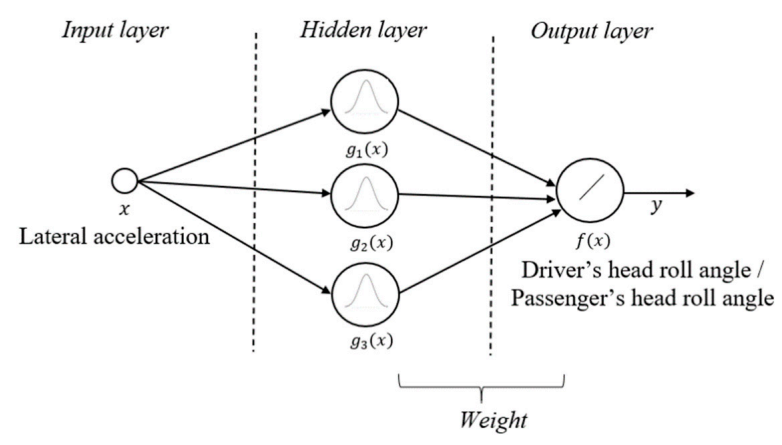

Figure 6. Structure of RBFNN.

The fixation of the number of hidden neurons is determined by Kolmogorov theorem. According to the theorem, the calculation of the number is done based on $2 n_{n}+1$ formula, where $n_{n}$ indicates the number of network input. Thus, based on that principle, the quantity of the hidden neurons used in this study is three for both driver's and passenger's model.

The data collection for the modeling purpose was realized by conducting an experiment that provokes MS. The prediction model developing process requires real time data of lateral acceleration and head roll responses. The experiment procedures are inspired by the previous works of Wada et al. [29]. Figure 7 illustrates the designated course. It is a slalom course where six cones are placed on $150 \mathrm{~m}$ road with $20 \mathrm{~m}$ gaps between each other. The nominal frequency of lateral acceleration during the slalom test is around $0.2 \mathrm{~Hz}$; a frequency that can aggravates MS.

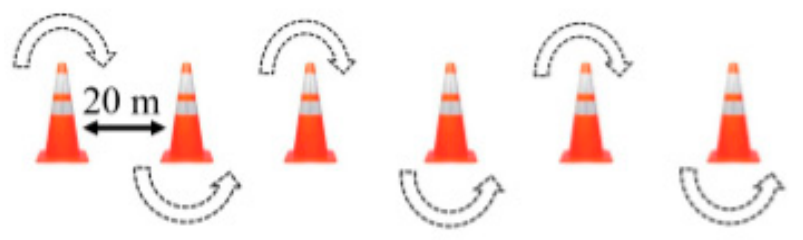

Figure 7. Designated course for data collection experiment.

Ten participants who give informed consent participated as drivers and passengers. The drivers are instructed to drive in slalom at a continuous velocity of $30 \mathrm{~km} / \mathrm{h}$. The driving behavior is categorized as normal driving irrespective of sex, skill and age. The data of lateral acceleration and head roll responses for both drivers and passengers are recorded by motion sensors, placed at the vehicle center of gravity (COG) and on the caps worn by the participants. The motion sensor used is an inertial measurement unit (IMU) device.

Details of the experiment and modeling process can be accessed in [25]. The network output is expressed as:

$$
y=g\left(\sum_{j=1}^{3} w_{j} \exp \left(\frac{-\left\|x-c_{j}\right\|^{2}}{\sigma^{2}}\right)+b_{2}\right)
$$

where, $w$ is the weight, $c$ is the centre point and $\sigma$ is the RBFNN spread. The value of $c, \sigma$ and $w$ for the driver's and passenger's models are given by [25]:

$$
\begin{array}{rlr}
\text { Driver's model: } & c=\left[\begin{array}{c}
-2.5560 \\
3.6721 \\
-0.6546
\end{array}\right], \sigma=\left[\begin{array}{l}
1.6 \\
1.6 \\
1.6
\end{array}\right], w=\left[\begin{array}{c}
8.6564 \\
-8.5897 \\
0.8409
\end{array}\right] \\
\text { Passenger's model: } & c=\left[\begin{array}{c}
-3.9402 \\
3.7988 \\
-3.6039
\end{array}\right], \sigma=\left[\begin{array}{l}
2.1 \\
2.1 \\
2.1
\end{array}\right], w=\left[\begin{array}{c}
14.5623 \\
11.6248 \\
-26.7979
\end{array}\right]
\end{array}
$$




\subsection{The Configuration of Fuzzy-PID Controller}

The fuzzy-PID controller is formed by a FLC with four scaling factors, $K_{e}, K_{d}, \beta, \alpha$ connected in series. $K_{e}$ and $K_{d}$ normalize the inputs to the range in which the inputs membership function (MF) are defined. In addition, $\beta$ and $\alpha$ normalize the output of the FLC to an applicable value [30]. The first input of the controller is head roll error, $e_{H}$ which is obtained from the difference of the desired/driver's head roll response, $\theta_{H D}$ and actual/passenger's head roll response, $\theta_{H P}$. The other input of the controller is the derivative of head roll error, $\dot{e}_{H}$. The output of the fuzzy-PID is as follow,

$$
\delta_{c}=\alpha U+\beta \int U d t
$$

where $U$ is the FLC output. The relation between input and output variables can be given as:

$$
U=A+P E+D \dot{E}
$$

where $E=K_{e} e_{H}$ and $\dot{E}=K_{d} \dot{e}_{H}$. Therefore, from (9) and (10), the fuzzy-PID controller output is:

$$
\delta_{c}=\alpha A+\beta A t+\alpha K_{e} P e_{H}+\beta K_{d} D \dot{e}_{H}+\beta K_{e} P \int e_{H} d t+\alpha K_{d} D \dot{e}_{H}
$$

Here, the FLC is designed based on the heuristic approach. It has two inputs and an output MF. Each of the MFs has a triangular and trapezoidal membership as shown in Figure 8. The input variables are decomposed into three varied fuzzy linguistic levels: Negative $(\mathrm{N})$, Zero $(\mathrm{Z})$ and Positive (P). Table 2 describes the control rules which are designed in IF-THEN structure.

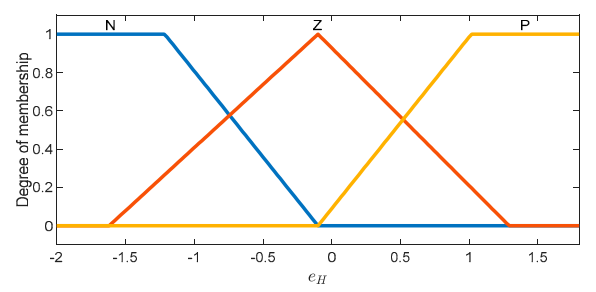

(a)

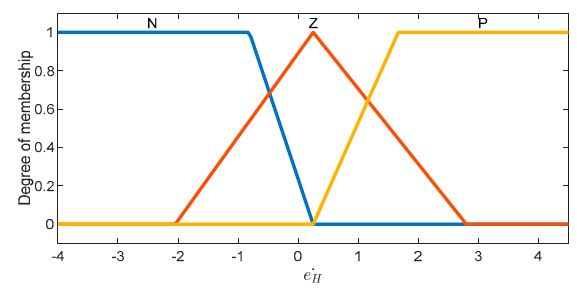

(b)

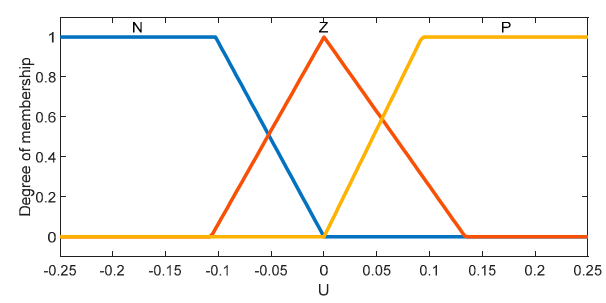

(c)

Figure 8. Membership function (MF) of input-output in fuzzy-PID, (a) MF of input $e_{H},(\mathbf{b}) \mathrm{MF}$ of input

\begin{tabular}{|c|c|c|c|}
\hline$\dot{e}_{H}$ & $\mathbf{N}$ & $\mathbf{Z}$ & $\mathbf{P}$ \\
\hline $\mathrm{N}$ & $\mathrm{P}$ & $\mathrm{P}$ & $P$ \\
\hline Z & Z & $\mathrm{Z}$ & Z \\
\hline $\mathrm{P}$ & $\mathrm{N}$ & $\mathrm{N}$ & $\mathrm{N}$ \\
\hline
\end{tabular}
$\dot{e}_{H}$ and (c) MF of output $U$.

Table 2. Fuzzy rules.

Particle swarm optimization (PSO) is utilized to select the scaling factors gain. The PSO fitness function is set to be the root-mean-square (RMS) value of lateral acceleration. The goal is to find a set 
of optimal values of the scaling factors by minimizing the fitness function. The fitness function can be formulated as:

$$
\text { Fitness function }=f\left(K_{e}, K_{d}, \beta, \alpha\right)=\sqrt{\frac{\sum\left[a_{y}(t)\right]^{2}}{N}}
$$

Table 3 tabulates the parameter of PSO. The parameter selection is mainly based on previous study [31]. After the optimization process, the gain value of the scaling factors is determined as, $K_{e}=1.3, K_{d}=1.43, \beta=0.9$ and $\alpha=-0.1$.

Table 3. Particle swarm optimization (PSO) parameter.

\begin{tabular}{cc}
\hline Parameter & Value \\
\hline Cognitive coefficient, $c$ & 1.42 \\
Social coefficient, $s$ & 1.42 \\
Inertial weight, $i w$ & 0.9 \\
Number of variables (dimensions), $N_{d}$ & $4\left(K_{e}, K_{d}, \alpha, \beta\right)$ \\
Upper bound limit & {$[1.3,1.5,0.9,0.1]$} \\
Lower bound limit & {$[0.8,0.9,0.1,0.2]$} \\
Number of particles, $N_{p}$ & 50 \\
Number of iterations, $N_{i}$ & 20 \\
\hline
\end{tabular}

\subsection{Motion Sickness Incidence (MSI) Quantification}

The efficiency of the suggested control structure is evaluated by calculating the passenger's MS level, before and after the inner loop system was applied to the control structure. Here, the MS is calculated through a 6 degrees-of-freedom (DOF) subjective vertical conflict (SVC) [32]. The model can quantify motion sickness incidence (MSI) which represents the severity level of MS. The mathematical 6-DOF-SVC model calculates the MSI based on the lateral acceleration and head roll responses. Therefore, this model is assumed to be a suitable method to quantify the MSI in this study.

\subsection{Driving Simulator Setup}

This study replaced the vehicle system model in the proposed control structure with a driving simulator to simulate the dynamics behavior of the autonomous vehicle in real time. The replacement of the autonomous vehicle by a driving simulator is due to the limited budget and safety reasons. The simulator is set to run at a speed of $30 \mathrm{~km} / \mathrm{h}$ constantly, according to the designated course in Figure 7. It is the same course that was used during the data collection experiment discussed previously in Section 2.4. The main PC and the simulator are connected by a crossover cable.

The objective of the experiment is to investigate the performance of the suggested MS minimization control system by evaluating the passenger's MSI index. The evaluation is undertaken by recording the movement of the passenger's head roll. At the same time, the data of the lateral acceleration is also collected. Then, the MSI of the participant is calculated based on the collected data of the lateral acceleration and head roll through the 6-DOF SVC model. The assessment is carried out by comparing the passenger's MSI before and after the implementation of the proposed inner loop control system into the overall control structure.

Ten healthy adults of random gender and age participated in this experiment. All the participants were required to give written informed consent before the experiment began. Figure 9 illustrates a participant who is sitting on the driving simulator while wearing a cap. The cap is attached with an IMU device as the motion sensor and worn to measure the participant's head roll angle. The participants are instructed to sit comfortably and to tilt their heads naturally according to the driving simulator's movement. 


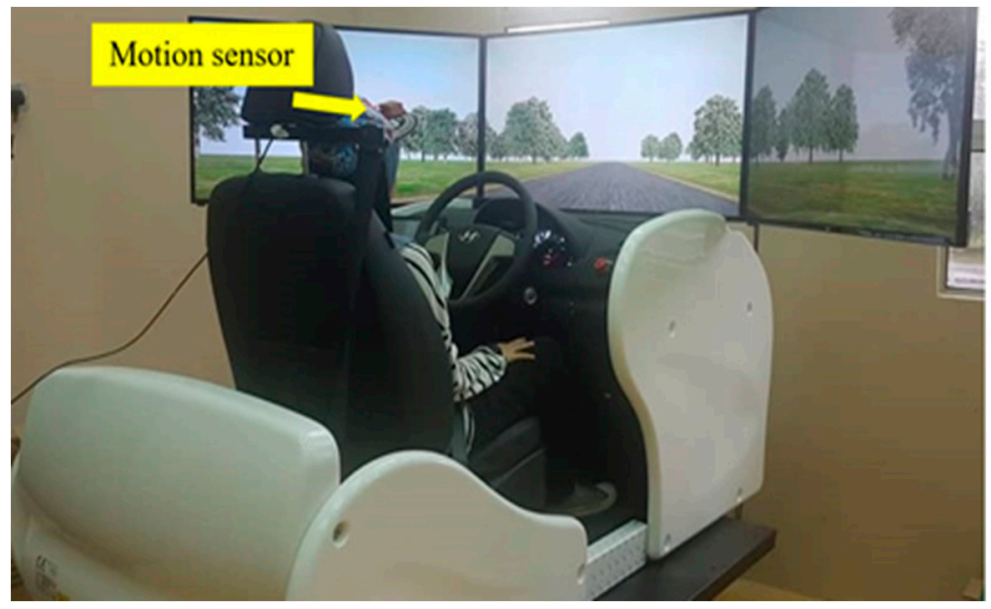

Figure 9. Overview of a participant sitting on the simulator.

\section{Results and Discussion}

As mentioned earlier, the objective of the proposed control system is to minimize the passenger's MS in an autonomous vehicle by diminishing the lateral acceleration. The lateral acceleration reduction would lead to the mitigation of the passenger's head roll movement towards the lateral acceleration direction, hence minimizing MS. Therefore, in this section, the responses of lateral acceleration, passenger's head roll and MSI are presented and discussed.

Figure 10 illustrates the lateral acceleration response before and after the inner loop system is applied. The result shows that the lateral acceleration slightly decreased in every peak of cornering. This finding indicates that the corrective wheel angle produced by the proposed fuzzy-PID controller managed to achieve the objective, which is to diminish the lateral acceleration.

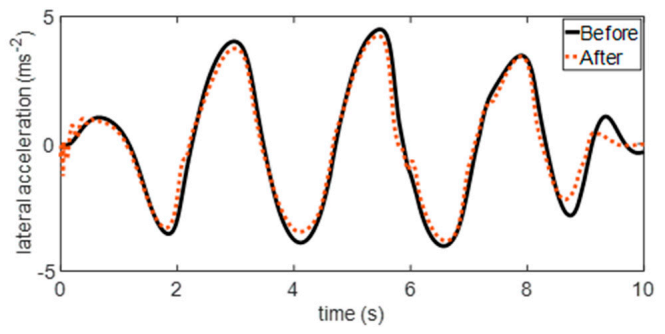

Figure 10. Lateral acceleration response.

Figure 11 shows the head roll responses of two participants before and after the implementation of the recommended inner loop control system. Due to the reduction of lateral acceleration, the head roll responses are decreasing as well.

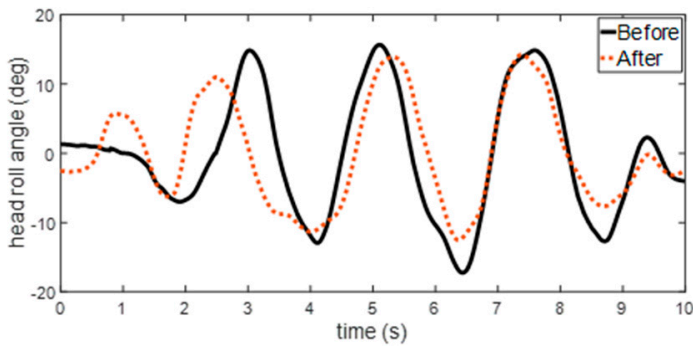

(a)

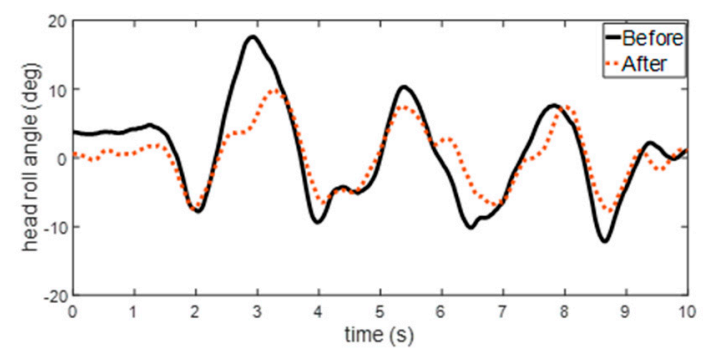

(b)

Figure 11. Head roll responses: (a) participant 1 and (b) participant 2. 
Finally, the MSI index of every participant is calculated. Table 4 tabulates the MSI percentage before and after the proposed inner loop system is included into the whole system. Even though the head roll angle responses among the participants are varied, overall, the MSI for every participant reduced by $3.95 \%$ in average. The results indicated that the proposed MS minimization control system consisting of the fuzzy-PID controller succeeded in achieving its objective.

Table 4. MSI results.

\begin{tabular}{cccc}
\hline Participant & Before (\%) & After (\%) & Reduction (\%) \\
\hline 1 & 0.003539 & 0.003417 & 3.45 \\
2 & 0.003269 & 0.003099 & 5.20 \\
3 & 0.003346 & 0.003218 & 3.83 \\
4 & 0.003431 & 0.003342 & 2.59 \\
5 & 0.003275 & 0.003159 & 3.54 \\
6 & 0.003401 & 0.003247 & 4.53 \\
7 & 0.003327 & 0.003202 & 3.76 \\
8 & 0.003527 & 0.003391 & 3.86 \\
9 & 0.003518 & 0.003375 & 4.06 \\
10 & 0.003327 & 0.003170 & 4.72 \\
Average & & & 3.95 \\
\hline
\end{tabular}

According to Table 4, the MSI has a small percentage value due to the short simulation time which was only $10 \mathrm{~s}$. Based on the previous research work, the difference between the driver's and passenger's MSI level escalated as time elapsed [32]. Thus, it is anticipated that the MSI decrement that can be achieved will be increase as the duration increases. To investigate the MSI value for a longer duration, the experiment is continued up to ten laps. Note that the pre-defined course shown in Figure 7 is referred to as single lap.

Table 5 tabulates the MSI results in a ten laps trajectory. The MSI for every participant was minimized by $11.49 \%$ on average after the application of the proposed inner loop system. As hypothesized, the MSI reduction percentages for the ten laps trajectory are higher than for the single lap trajectory. Hence, this finding agrees with the previous study in [32].

Table 5. MSI results for ten laps trajectory.

\begin{tabular}{cccc}
\hline Participant & Before (\%) & After (\%) & Reduction (\%) \\
\hline 1 & 0.2140 & 0.1804 & 15.70 \\
2 & 0.1996 & 0.1787 & 10.47 \\
3 & 0.1939 & 0.1733 & 10.62 \\
4 & 0.2093 & 0.1863 & 10.99 \\
5 & 0.1874 & 0.1703 & 9.12 \\
6 & 0.2094 & 0.1848 & 11.75 \\
7 & 0.2159 & 0.1912 & 11.44 \\
8 & 0.2029 & 0.1804 & 11.09 \\
9 & 0.1951 & 0.1729 & 11.38 \\
10 & 0.2127 & 0.1865 & 12.32 \\
Average & & & 11.49 \\
\hline
\end{tabular}

\section{Conclusions and Future Work}

In terms of MS occurrence factors, there is an existing correlation with the steering, lateral acceleration and head roll. This correlation makes it possible to implement the usage of head roll as the controlled variable to generate an additional corrective wheel angle in mitigating MS, by reducing the lateral acceleration. It is compulsory to utilize a controller to compute the corrective wheel angle. Therefore, this study proposed the utilization of a fuzzy-PID controller for a MS minimization control strategy for an autonomous vehicle. The aim of the control structure which is inspired by an active steering system is to diminish the vehicle lateral acceleration. The reduction of the lateral acceleration will then minimize the head roll angle with respect to the lateral acceleration 
direction, thus mitigating the MSI of the passenger. The gain parameters of the fuzzy-PID controller are tuned by heuristic and PSO methods.

It is necessary to use estimated head roll response instead of the real response as the controlled variable, because it is considered inappropriate to measure the occupant's head tilt movement during travelling. Thus, the RBFNN modeling method is utilized to develop prediction models to estimate both driver's and passenger's head roll responses. An experiment that can provoke MS is set to acquire data for the RBFNN modeling process.

The efficiency of the proposed control system is evaluated by investigating the MSI index of ten participants using a driving simulator to represent the real autonomous vehicle. The experiment results indicated that the MSI for single and ten laps trajectories are lowered by 3.95\% and $11.49 \%$ in average, respectively. Hence, it is proven that the recommended control strategy consisting of a fuzzy-PID controller managed to mitigate the passenger's MS level by reducing the lateral acceleration, as compared to the system without the controller utilization.

In the future, the evaluation of the proposed control system performance can be improvised through a series of tests in different trajectories. The control system can also be improvised by redesigning the head roll prediction modeling process using various trajectories and speeds. The enhancement in the modeling process can also increase the generalization capability of the prediction models. Lastly, it is suggested that to validate the proposed control strategy, a real driving test should be performed in order to examine its effectiveness in a real driving environment.

Author Contributions: Conceptualization, M.H.M.A. and H.Z.; methodology, N.H.A., N.W. and N.H.; software, S.'A.S., N.H.A. and N.W.; validation, S.'A.S.; formal analysis, S.'A.S., N.W. and N.H.; investigation, S.'A.S.; resources, M.H.M.A., K.A.A.K. and H.Z.; data curation, S.'A.S. and N.H.; writing-original draft preparation, S.'A.S.; writing-review and editing, M.H.M.A.; visualization, S.'A.S.; supervision, M.H.M.A. and H.Z.; project administration, M.H.M.A. and H.Z.; funding acquisition, M.H.M.A. and K.A.A.K. All authors have read and agreed to the published version of the manuscript.

Funding: This work was funded by Ministry of Higher Education Malaysia (MoHE) through Universiti Teknologi Malaysia (UTM) Fundamental Research Grant Scheme (FRGS/1/2019/TK08/UTM/02/10) Vot No.: R.K130000.7843.5F204 and Malaysian Institute of Road Safety Research (MIROS) through Asean NCAP Colaborative Holistic Research Grant (ANCHOR- PHASE 3) Vot No.: R.K130000.7343.4B582.

Acknowledgments: My sincere gratitude goes to the students of Universiti Teknologi Malaysia, Kuala Lumpur campus who actively participated in the experiment.

Conflicts of Interest: The authors declare no conflict of interest.

\section{Nomenclature}

$\begin{array}{ll}\text { MS } & \text { motion sickness } \\ \text { FLC } & \text { Fuzzy Logic Controller } \\ \text { SI } & \text { System Identification } \\ \text { TDNN } & \text { Time Delay Neural Network } \\ \text { RBFNN } & \text { Radial Basis Function Neural Network } \\ \text { COG } & \text { Center of gravity } \\ \text { N } & \text { Negative } \\ \text { P } & \text { Positive } \\ \text { MSI } & \text { motion sickness incidence } \\ \text { DSA } & \text { Dynamic Speed Adaptation } \\ \text { PID } & \text { Proportional Integral Derivative } \\ \text { ANN } & \text { Artificial Neural Network } \\ \text { PSO } & \text { Particle Swarm Optimisation } \\ \text { DOF } & \text { Degreeoffreedom } \\ \text { MF } & \text { Membership function } \\ \text { Z } & \text { Zero } \\ \text { SVC } & \text { Subjective Vertical Conflict } \\ \text { IMU } & \text { Inertial Measurement Unit }\end{array}$




\section{References}

1. Chan, C.-Y. Advancements, prospects, and impacts of automated driving systems. Int. J. Transp. Sci. Technol. 2017, 6, 208-216. [CrossRef]

2. Offer, G.J. Automated vehicles and electrification of transport. Energy Environ. Sci. 2015, 8, 26-30. [CrossRef]

3. Diels, C.; Bos, J.E. Self-driving carsickness. Appl. Ergon. 2016, 53, 374-382. [CrossRef] [PubMed]

4. Diels, C. Will autonomous vehicles make us sick? Contemp. Ergon. Hum. Factors 2014, 301-307. [CrossRef]

5. Lackner, J.R. Motion sickness: More than nausea and vomiting. Exp. Brain Res. 2014, 232, 2493-2510. [CrossRef]

6. Wada, T.; Fujisawa, S.; Imaizumi, K.; Kamiji, N.; Doi, S. Effect of Driver's Head Tilt Strategy on Motion Sickness Incidence. IFAC Proc. Vol. 2010, 43, 192-197. [CrossRef]

7. Wada, T.; Konno, H.; Fujisawa, S.; Doi, S. Can passengers' active head tilt decrease the severity of carsickness? Effect of head tilt on severity of motion sickness in a lateral acceleration environment. Hum. Factors J. Hum. Factors Ergon. Soc. 2012, 54, 226-234. [CrossRef]

8. Konno, H.; Fujisawa, S.; Wada, T.; Doi, S. Analysis of motion sensation of car drivers and its application to posture control device. In Proceedings of the SICE Annual Conference, Tokyo, Japan, 13-18 September 2011; pp. 192-197.

9. Fujisawa, S.; Wada, T.; Konno, H.; Doi, S. Analysis of Head-tilt Strategy of Car Drivers and Its Application to Passenger's Posture Control Device. Trans. Soc. Instrum. Control. Eng. 2012, 48, 60-66. [CrossRef]

10. Turner, M.; Griffin, M. Motion sickness in public road transport: The effect of driver, route and vehicle. Ergonomics 1999, 42, 1646-1664. [CrossRef]

11. Elbanhawi, M.; Simic, M.; Jazar, R. In the Passenger Seat: Investigating Ride Comfort Measures in Autonomous Cars. IEEE Intell. Transp. Syst. Mag. 2015, 7, 4-17. [CrossRef]

12. Elbanhawi, M.; Simic, M.; Jazar, R. The Role of Path Continuity in Lateral Vehicle Control. Procedia Comput. Sci. 2015, 60, 1289-1298. [CrossRef]

13. Serna, C.G.; Ruichek, Y. Dynamic Speed Adaptation for Path Tracking Based on Curvature Information and Speed Limits. Sensors 2017, 17, 1383. [CrossRef] [PubMed]

14. Ren, Y.; Zheng, L.; Khajepour, A. Integrated model predictive and torque vectoring control for path tracking of 4-wheel-driven autonomous vehicles. IET Intell. Transp. Syst. 2019, 13, 98-107. [CrossRef]

15. Aripin, M.K.; Danapalasingam, K.A.; Peng, K.; Hamzah, N.; Sam, Y.; Ismail, M.F. A Review of Active Yaw Control System for Vehicle Handling and Stability Enhancement. Int. J. Veh. Technol. 2014, 2014, 437515. [CrossRef]

16. Saruchi, S.'A.; Ariff, M.H.M.; Zamzuri, H.; Amer, N.H.; Wahid, N.; Hassan, N.; Kadir, Z.A. Lateral control strategy based on head movement responses for motion sickness mitigation in autonomous vehicle. J. Braz. Soc. Mech. Sci. Eng. 2020, 42,1-14. [CrossRef]

17. Kumar, S.; Nagpal, P. Comparative analysis of P, PI, PID and fuzzy logic controller for tank water level control system. Int. Res. J. Eng. Technol. 2017, 4, 1174-1177.

18. Bharti, R.; Trivedi, R.; Padhy, P.K. Design of Optimized PID Type Fuzzy Logic Controller for Higher Order System. In Proceedings of the 5th International Conference on Signal Processing and Integrated Networks (SPIN), Noida, India, 22-23 February 2018; pp. 760-764.

19. Aras, M.S.M.; Azmi, M.W.N.; Kamaruddin, M.N.; Harun, M.H.; Kasno, M.A. A study of tuning process of fuzzy logic controller output membership function for AUV-pitch control. In Proceedings of the IEEE 7th International Conference on Underwater System Technology: Theory and Applications (USYS), Kuala Lumpur, Malaysia, 18-20 December 2017; pp. 1-5.

20. Kim, J.-Y.; Kim, H.-M.; Kim, S.-K.; Jeon, J.-H.; Choi, H.-K. Designing an Energy Storage System Fuzzy PID Controller for Microgrid Islanded Operation. Energies 2011, 4, 1443-1460. [CrossRef]

21. Saruchi, S.'A.; Zamzuri, H.; Hassan, N.; Ariff, M.H.M. Modeling of head movements towards lateral acceleration direction via system identification for motion sickness study. In Proceedings of the International Conference on Information and Communications Technology (ICOIACT), Yogyakarta, Indonesia, 6-7 March 2018; pp. 633-638.

22. Saruchi, S.'A.; Ariff, M.H.M.; Zamzuri, H.; Hassan, N.; Wahid, N.; Zakaria, N.J. The correlation model of head roll and lateral acceleration during curve driving via Hammerstein-Wiener. Int. J. Innov. Technol. Explor. Eng. 2019, 8, 2586-2590.

23. Saruchi, S.'A.; Ariff, M.H.M.; Zamzuri, H.; Hassan, N.; Wahid, N. Artificial neural network for modelling of the correlation between lateral acceleration and head movement in a motion sickness study. IET Intell. Transp. Syst. 2019, 13, 340-346. [CrossRef] 
24. Saruchi, S.A.; Ariff, M.H.; Zamzuri, H.; Hassan, N.; Wahid, N. Modeling of occupant's head movement behavior in motion sickness study via time delay neural network. Simulation 2019, 96, 131-140. [CrossRef]

25. Saruchi, S.'A.; Ariff, M.H.M.; Shapiai, M.I.; Hassan, N.; Wahid, N.; Zakaria, N.J.; Rahman, M.A.A.; Zamzuri, H. Radial basis function neural network for head roll prediction modelling in a motion sickness study. Indones. J. Electr. Eng. Comput. Sci. 2019, 15, 1637-1644. [CrossRef]

26. Osborn, R.P.; Shim, T. Independent control of all-wheel-drive torque distribution. Veh. Syst. Dyn. 2006, 44, 529-546. [CrossRef]

27. Nagai, M.; Shino, M.; Gao, F. Study on integrated control of active front steer angle and direct yaw moment. JSAE Rev. 2002, 23, 309-315. [CrossRef]

28. Hoffmann, G.M.; Tomlin, C.J.; Montemerlo, M.; Thrun, S. Autonomous Automobile Trajectory Tracking for Off-Road Driving: Controller Design, Experimental Validation and Racing. In Proceedings of the American Control Conference, New York, NY, USA, 9 July 2007; pp. 2296-2301.

29. Wada, T.; Kamiji, N.; Doi, S. A mathematical model of motion sickness in 6DOF motion and its application to vehicle passengers. arXiv 2013, arXiv:1504.05261.

30. Karasakal, O.; Güzelkaya, M.; Eksin, I.; Yesil, E.; Kumbasar, T. Online tuning of fuzzy PID controllers via rule weighing based on normalized acceleration. Eng. Appl. Artif. Intell. 2013, 26, 184-197. [CrossRef]

31. Khairuddin, I.M.; Dahalan, A.S.A.; Abidin, A.F.Z.; Lai, Y.Y.; Nordin, N.A.; Sulaiman, S.F.; Jaafar, H.I.; Mohamad, S.H.; Amer, N.H. Modeling and Simulation of Swarm Intelligence Algorithms for Parameters Tuning of PID Controller in Industrial Couple Tank System. Adv. Mater. Res. 2014, 903, 321-326. [CrossRef]

32. Wada, T.; Fujisawa, S.; Doi, S. Analysis of driver's head tilt using a mathematical model of motion sickness. Int. J. Ind. Ergon. 2018, 63, 89-97. [CrossRef]

(C) 2020 by the authors. Licensee MDPI, Basel, Switzerland. This article is an open access article distributed under the terms and conditions of the Creative Commons Attribution (CC BY) license (http://creativecommons.org/licenses/by/4.0/). 